\title{
UJI BEBERAPA JENIS PUPUK NITROGEN LEPAS LAMBAT PADA TANAMAN KUBIS BUNGA (Brassica oleraceae var. botrytis L.) YANG DIBERI PUPUK DASAR NPK
}

\section{THE TESTING OF SEVERAL TYPES OF SLOW RELEASE NITROGEN FERTILIZER ON CAULIFLOWER (Brassica oleraceae var. botrytis L.) WITH ADDITION OF NPK BASIC FERTILIZER}

\author{
Diko Sri Agung ${ }^{1}$, Yohannes Cahya Ginting ${ }^{1}$, Rugayah ${ }^{1}$ dan Lilis Hermida ${ }^{2 *}$ \\ ${ }^{1}$ Jurusan Agroteknologi Fakultas Pertanian Universitas Lampung, Bandar Lampung, Indonesia \\ ${ }^{2}$ Jurusan Teknik Kimia Fakultas Teknik Universitas Lampung, Bandar Lampung, Indonesia \\ *Email: lilis.hermida@engunila.ac.id \\ * Corresponding Author, Diterima: 10 Mei 2021, Direvisi: 24 Juni 2021, Disetujui: 30 Ags. 2021
}

\begin{abstract}
Conventional urea fertilizer which is easily lost and leached in the soil can be overcome by modifying the physical and chemical form of conventional urea fertilizer into Slow Release Urea (SRU). This study aimed to (1) determine the effect of the application of several types of slow-release nitrogen source fertilizers on the growth and yield of cauliflower. (2) determine the type of slow-release fertilizer N (nitrogen) which has the best effect on the growth and yield of cauliflower. This research was conducted in Bukit Kemiling Permai, Bandar Lampung from March to June 2019. This study used a Randomized Block Design (RAK). Five treatments in this study were P0 (Control), P1 (Urea), P2 (SRU Bentonite), P3 (SRU Baggase Bottom Ash (BBA)), and P4 (SRU Mesoporous) repeated four times. The results showed that the effect of various types of slow-release nitrogen source fertilizer on cauliflower was not different compared to conventional urea and without fertilization. In general, slow-release urea fertilizer was superior to conventional urea fertilizer in terms of plant crown width, leaf length, leaf width, harvest time, curd weight, and curd diameter, but the differences were not significant. Messopori type SRU (slow release urea) fertilizer treatment tended to produce heavier leaf dry weight than SRU (slow release urea) BBA fertilizer with a difference of $1.84 \mathrm{~g}(19.81 \%)$.
\end{abstract}

Keywords: Cauliflower, conventional urea, slow release urea.

\begin{abstract}
ABSTRAK
Pupuk urea konvensional yang mudah hilang dan tercuci di tanah dapat diatasi dengan memodifikasi bentuk fisika dan kimia pupuk urea konvensional menjadi pupuk urea lepas lambat (Slow Release Urea $=S R U$ ). Penelitian ini bertujuan untuk (1) mengetahui pengaruh pemberian beberapa jenis pupuk sumber nitrogen lepas lambat terhadap pertumbuhan dan hasil kubis bunga. (2) mengetahui jenis pupuk sumber $\mathrm{N}$ (nitrogen) lepas lambat yang paling baik pengaruhnya terhadap pertumbuhan dan hasil kubis bunga. Penelitian ini dilakukan di Bukit Kemiling Permai, Kota Bandar Lampung pada bulan Maret sampai dengan Juni 2019. Penelitian ini menggunakan Rancangan Acak Kelompok (RAK). Lima perlakuan dalam penelitian ini adalah $\mathrm{P}_{0}$ (Kontrol), $\mathrm{P}_{1}(\mathrm{Urea}), \mathrm{P}_{2}$ (SRU Bentonit),
\end{abstract}


$\mathrm{P}_{3}$ (SRU Baggase Bottom Ash (BBA)), dan $\mathrm{P}_{4}$ (SRU Mesopori) yang diulang sebanyak empat kali. Hasil penelitian menunjukkan bahwa pengaruh berbagai jenis pupuk sumber nitrogen lepas lambat pada tanaman kubis bunga tidak berbeda dengan urea konvensional dan tanpa pemupukan. Secara umum, pupuk urea lepas lambat lebih unggul dibandingkan dengan pupuk urea konvensional dalam hal lebar tajuk tanaman, panjang daun, lebar daun, waktu panen, bobot curd, dan diameter curd, namun pebedaannya tidak signifikan. Pemberian perlakuan pupuk SRU (slow release urea) jenis Messopori cenderung menghasilkan bobot kering daun yang lebih berat dibandingkan dengan pupuk SRU (slow release urea) jenis BBA dengan selisih 1,84 g (19,81\%).

Kata kunci : Kubis bunga, slow release urea, urea konvensional.

\section{PENDAHULUAN}

Kubis bunga (Brassica oleraceae Var. botritys

L) merupakan tanaman sayuran yang berasal dari daerah sub tropis. Temperatur untuk pertumbuhan kubis bunga yaitu minimum $15.5-18^{\circ} \mathrm{C}$ dan maksimum $24^{\circ}$

C. Kelembaban optimum bagi tanaman ini antara 8090\%. Namun dewasa ini telah dikembangkan beberapa varietas yang dapat membentuk bunga di dataran rendah, diantaranya adalah PM 126 F1, Diamond dan Mona. Dengan diciptakannya kultivar baru yang lebih tahan terhadap temperatur tinggi, Budidaya kubis bunga juga dapat dilakukan di dataran rendah (0-200 m dpl) dan menengah (200-700 m dpl) (Direktorat Budidaya Tanaman Sayuran dan Biofarmaka, 2007). Marliah et al. (2013) menyebutkan bahwa keunggulan PM 126 F1 adalah pada produktivitas yang tinggi dan krop membentuk kubah berwarna putih.

Supaya pertumbuhan kubis bunga dapat maksimal maka dibutuhkan sumber unsur hara yang cukup. Salah satu unsur hara yang dibutuhkan tanaman untuk pembentukan jaringan adalah unsur nitrogen yang dibutuhkan dalam jumlah banyak. Kebutuhan tanaman akan $\mathrm{N}$ lebih tinggi dibandingkan dengan unsur hara lainnya. Kekurangan $\mathrm{N}$ akan menyebabkan tanaman tidak tumbuh secara optimum (Sutedjo, 2010). Salah satu pupuk sumber nitrogen yang umum digunakan oleh petani adalah urea. Pupuk urea memiliki kandungan unsur hara tunggal yaitu nitrogen sebesar 46\%. Pupuk urea memiliki sifat yang mudah menguap dan mudah larut dalam air sehingga efisiensinya rendah karena pupuk urea harus diaplikasikan berkali-kali.

Upaya untuk menyediakan unsur hara nitrogen dalam tanah agar tidak mudah hilang adalah dengan memodifikasi bentuk fisik dan kimia pupuk urea konvensional menjadi pupuk urea lepas lambat. Prinsip kerja pupuk urea lepas lambat ini dengan memperlambat proses hidrolisis urea di dalam tanah. Pelepasan zat hara tersebut sesuai dengan waktu dan jumlah yang dibutuhkan tanaman, serta mempertahankan keberadaan pupuk dalam tanah sehingga penyerapan oleh tanaman lebih optimal. SRU memberikan banyak manfaat potensial bagi tanaman karena memberikan durasi pelepasan nitrogen yang lebih lama daripada pupuk urea konvensional (Landschoot, 2015 ).

Penggunaan pupuk urea lepas lambat diharapkan dapat mengurangi tingkat kehilangan nitrogen dan ketersediannya dalam tanah lebih lama. Dengan demikian jumlah pupuk urea yang akan diaplikasikan ke dalam tanah lebih sedikit dan tidak perlu berkali-kali. 
Tujuan dari penelitian ini adalah mengetahui pengaruh pemberian beberapa jenis pupuk sumber $\mathrm{N}$ (nitrogen) lepas lambat terhadap pertumbuhan dan hasil kubis bunga serta mengetahui jenis pupuk sumber $\mathrm{N}$ (nitrogen) lepas lambat yang paling baik pengaruhnya terhadap pertumbuhan dan hasil kubis bunga.

\section{BAHAN DAN METODE}

Penelitian ini dilakukan di Bukit Kemiling Permai, Kota Bandar Lampung, pada bulan Maret sampai dengan Juni 2019. Alat-alat yang digunakan dalam penelitian ialah tray pembibitan, gembor, cangkul, sabit, meteran, koret, hand sprayer, bambu, tali rapia, gunting, kertas lebel, timbangan, penggaris, kamera, jangka sorong, dan alat tulis. Sedangkan bahan yang digunakan ialah benih kubis bunga PM 126 F1, media semai, pupuk urea lepas lambat, pupuk NPK, fungisida, insektisida dan air. Penelitian ini menggunakan Rancangan Acak Kelompok (RAK). Lima perlakuan dalam penelitian ini adalah $\mathrm{P}_{0}$ (Kontrol), $\mathrm{P}_{1}$ (Urea), $\mathrm{P}_{2}$ (SRU Bentonit), $\mathrm{P}_{3}$ (SRU BBA), dan $\mathrm{P}_{4}$ (SRU Mesopori) yang diulang sebanyak empat kali. Analisis tanah awal dilakukan sebelum dilakukan penanaman dan pengaplikasian pupuk. Sampel tanah diambil pada kedalaman $10 \mathrm{~cm}$ dengan tiga titik pengambilan secara zig-zag dari semua petakan dan diakumulasikan menjadi satu. Penyemaian dilakukan pada media semai campuran tanah halus dan kompos dengan perbandingan 2:1 dan dipindahkan ke kotak semai. Bibit kubis bunga yang telah berumur 14 hari dipindahkan ke contongan. Penyiapan lahan diawali dengan tanah digemburkan dan ditambahakan sekam padi kemudian dibuat petak percobaan sebanyak 20 petakan dengan 5 perlakuan dan 4 ulangan berukuran $1 \mathrm{~m} \times 2 \mathrm{~m}$. Bibit yang telah berumur 4 minggu dan memiliki 4-6 helai daun dipindah tanam dengan jarak tanam $30 \mathrm{~cm}$ x $40 \mathrm{~cm}$. Pemupukan dilakukan dengan pupuk NPK sebagai pupuk dasar yang diberikan pada saat tanaman berumur satu hari setelah pindah tanam sebanyak $600 \mathrm{~kg} / \mathrm{ha}$-atau $12 \mathrm{~g}$ per tanaman, pupuk urea dengan dosis $4 \mathrm{~g}$ per tanaman dan pupuk urea lepas lambat dengan dosis yang 4,4 g per tanaman. Pemeliharaan tanaman yang dilakukan adalah penyiraman, penyiangan gulma, pembumbunan, dan pengendalian hama dan penyakit. Pemanenan dilakukan saat kubis bunga telah memasuki umur panen yaitu 45-50 HST (hari setelah tanam)

Variabel yang diamati pada penelitian ini yaitu tinggi tanaman, jumlah daun, lebar tajuk, panjang daun, lebar daun, diameter batang, waktu muncul curd, waktu panen, diameter curd per tanaman, bobot curd per tanaman, dan bobot kering brangkasan.

\section{HASIL DAN PEMBAHASAN}

Pada penelitian ini pemberian berbagai jenis pupuk sumber nitrogen lepas lambat pada tanaman kubis bunga tidak menunjukkan adanya perbedaan pengaruh dengan pemberian urea konvensional dan tanpa pemupukan. Hal ini diduga karena beberapa faktor di antaranya kekurangan air pada masa generatif yang sangat mempengaruhi hasil produksi tanaman. Pada penelitian ini tanaman kubis bunga terserang penyakit busuk pangkal batang yang ditandai dengan pangkal batang mengalami pembusukan berwarna kecoklatan dan lembek, serta terdapat bercak putih (Gambar 1). Kemudian terserang hama ulat tritip atau 


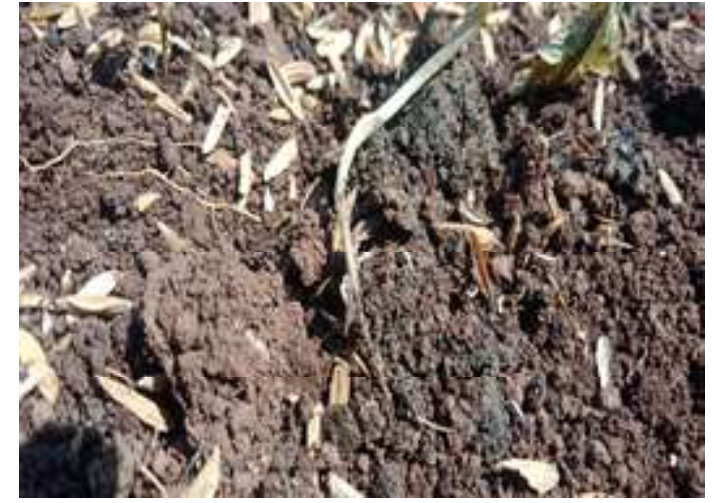

Gambar 1. Tanaman kubis bunga yang terserang jamur penyakit busuk pangka batang.

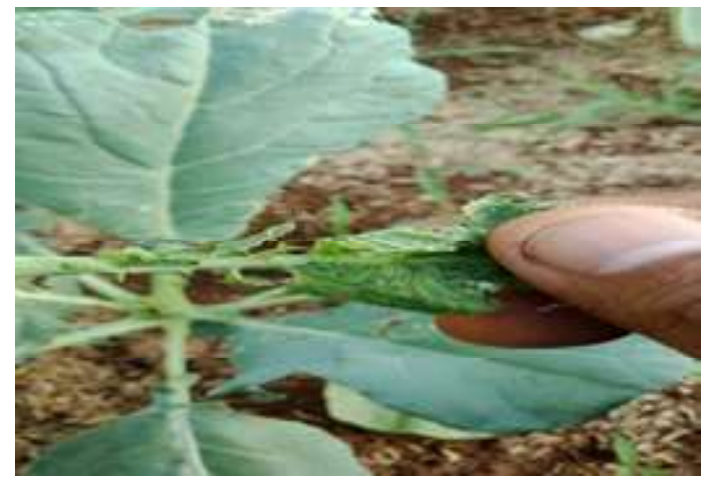

Gambar 2. Tanaman kubis bunga yang terserang hama ulat tritip (Plutella maculipennis).

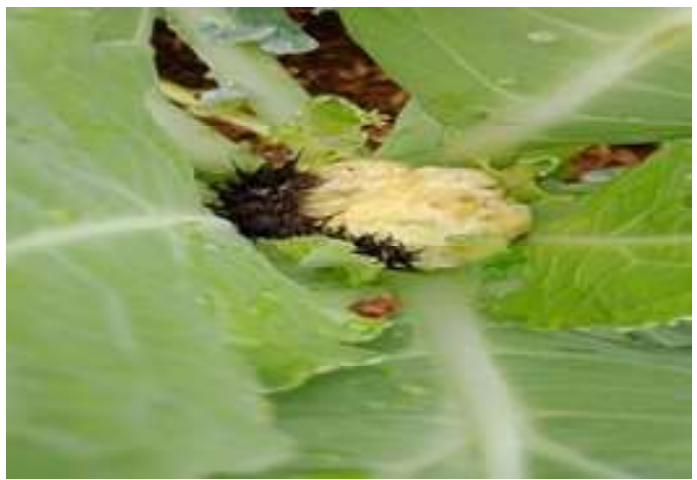

Gambar 3. Curd kubis bunga yang terserang hama ulat tritip (Plutella maculipennis) dewasa.

ngengat punggung berlian (Plutella maculipennis)

(Gambar 2). Larva plutella maculipennis memakan daging daun dan meninggalkan kulit ari sehingga tanaman menampakkan noda-noda putih (Kalshoven, 1981). Pada percobaan yang dilakukan Sunarti (2015) ulat tritip atau ngengat punggung berlian (Plutella maculipennis) juga memakan bunga kol sehingga bunga kol menjadi tidak utuh lagi (Gambar 3).

Akibat beberapa faktor tersebut maka diduga pertumbuhan tanaman tidak optimal sehingga respon terhadap perlakuan yang diberikan tidak maksimal. Padahal berdasarkan penelitian Suryani (2018) menunjukkan bahwa pemberian berbagai jenis pupuk sumber nitrogen menghasilkan pertumbuhan tinggi tanaman, jumlah daun, ukuran daun, waktu muncul curd, waktu panen curd, diameter curd, bobot curd, bobot brangkasan dan bobot kering akar yang lebih tinggi dibandingkan tanpa pemupukan.

Pemberian pupuk urea konvensional menunjukan hasil yang berbeda nyata dibandingkan dengan perlakuan pupuk SRU pada variabel waktu muncul curd dengan selisih 2,85 hari setelah tanam (Tabel 1). Berdasarkan hasil penelitian Suryani (2018) pupuk urea konvensional menghasilkan waktu muncul curd lebih cepat dibandingkan dengan pupuk SRU.

Pemberian perlakuan pupuk SRU jenis Messopori secara nyata memberikan hasil bobot kering daun yang lebih berat dibandingkan dengan pupuk SRU jenis BBA dengan selisih 1,84 g(Tabel2). Hal ini sesuai dengan hasil penelitian Suryani (2018) yang dilakukan di dalam rumah kaca, bahwa pemberian pupuk SRU Mesopori menghasilkan bobot kering brangkasan yang lebih berat dibandingkan SRU BBA.

Dari berbagai jenis pupuk sumber nitrogen yang digunakan, pupuk SRU jenis Bentonit cenderung menghasilkan bobot curd yang lebih tinggi dibandingkan dengan pupuk urea konvensional dengan selisih 4,79 g per tanaman atau setara dengan $299 \mathrm{~kg} / \mathrm{ha}$ (Tabel 3). 
Tabel 1. Pengaruh pemberian berbagai jenis pupuk sumber nitrogen terhadap waktu muncul curd.

\begin{tabular}{lccc}
\hline \multirow{2}{*}{\multicolumn{1}{c}{ Perbandingan }} & \multicolumn{2}{c}{ Selisih } & \multirow{2}{*}{ F-hitung } \\
\cline { 2 - 3 } & $45,05-44,69=0,36$ & 0,81 & $0,10^{\text {tn }}$ \\
\hline U1 : Kontrol vs Pemupukan & $42,55-45,40=-2,85$ & 6,28 & $5,85^{*}$ \\
U2 : Urea vs SRU & $45,20-45,50=-0,30$ & 0,66 & $0,06^{\text {th }}$ \\
U3 : Bentonit vs BBA, Mesopori & $45,25-45,75=-0,50$ & 1,09 & $0,12^{\text {tn }}$ \\
U4 : BBA vs Mesopori &
\end{tabular}

Keterangan : Nilai F-Tabel pada taraf $5 \%=4,75, \mathrm{tn}=$ Tidak berbeda nyata pada taraf $5 \%, *=$ Berbeda nyata pada taraf $5 \%$.

Tabel 2. Pengaruh pemberian berbagai jenis pupuk sumber nitrogen terhadap bobot kering daun.

\begin{tabular}{|c|c|c|c|}
\hline \multirow{2}{*}{ Perbandingan } & \multicolumn{2}{|c|}{ Selisih } & \multirow{2}{*}{ F-hitung } \\
\hline & Gram & $\%$ & \\
\hline U1 : Kontrol vs Pemupukan & $9,03-8,38=0,65$ & 7,74 & $1,36^{\mathrm{tn}}$ \\
\hline U2 : Urea vs SRU & $8,57-8,32=0,25$ & 3,00 & $0,19^{\text {tn }}$ \\
\hline U3 : Bentonit vs BBA, Mesopori & $8,22-8,37=-0,15$ & 1,71 & $0,06^{\mathrm{tn}}$ \\
\hline U4 : BBA vs Mesopori & $7,45-9,29=-1,84$ & 19,81 & $6,82^{*}$ \\
\hline
\end{tabular}

Keterangan : Nilai F-Tabel pada taraf $5 \%=4,75$, tn $=$ Tidak berbeda nyata pada taraf $5 \%, *=$ Berbeda nyata pada taraf $5 \%$.

Tabel 3. Pengaruh pemberian berbagai jenis pupuk sumber nitrogen terhadap bobot curd.

\begin{tabular}{lccc}
\hline \multirow{2}{*}{\multicolumn{1}{c}{ Perbandingan }} & Gram & \multirow{2}{*}{ F-hitung } \\
\cline { 2 - 3 } & $156,73-160,72=-3,99$ & 2,49 & $0,13^{\text {tn }}$ \\
\hline U1 : Kontrol vs Pemupukan & $157,13-161,92=-4,79$ & 2,96 & $0,17^{\text {tn }}$ \\
U2 : Urea vs SRU & $172,42-156,67=15,75$ & 10,05 & $1,66^{\text {tn }}$ \\
U3 : Bentonit vs BBA, Mesopori & $151,79-161,56=-9,77$ & 6,04 & $0,48^{\text {tn }}$ \\
\hline U4 : BBA vs Mesopori &
\end{tabular}

Keterangan : Nilai F-Tabel pada taraf $5 \%=4,75$, tn $=$ Tidak berbeda nyata pada taraf $5 \%$.

Menurut Suwardi (1991) pupuk dalam bentuk lepas lambat atau slow release dapat mengoptimalkan penyerapan nitrogen oleh tanaman karena SRU dapat mengendalikan pelepasan nitrogen sesuai kebutuhan tanaman sehingga pupuk yang diberikan lebih efisien dibandingkan dengan pupuk urea konvensional.

Dari berbagai jenis pupuk sumber nitrogen lepas lambat yang digunakan, ada kecenderungan bahwa jenis pupuk SRU Bentonit berpotensi dikembangkan untuk meningkatkan hasil tanaman kubis bunga. Pemberian pupuk SRU jenis Bentonit cenderung menghasilkan bobot kubis bunga yang lebih baik dibandingkan dengan pupuk SRU jenis BBA dan Messopori dengan selisih $15,75 \mathrm{~g}$ per tanaman atau
$984 \mathrm{~kg} / \mathrm{ha}$ (Tabel 3). Hal tersebut menunjukkan bahwa penggunaan pupuk SRU Bentonit mampu meningkatkan hasil tanaman kubis bunga. Hal ini diduga karena SRU Bentonit yang mempunyai kandungan utama mineralsmektit (montmorillonit) yang mengandung silika dengan kadar 85-95\%, bersifat plastis dan koloidal tinggi dan berbentuk padat, keras dan tidak memiliki pori-pari (Ekaputri et all., 2007).

Data hasil analisis tanah awal menunjukkan bahwa $\mathrm{pH}$ dari tanah yang digunakan sebagai media pertanaman kubis bunga pada penelitian ini sebelum diberikan perlakuan adalah 6,07 (Tabel 4). Analisis tanah setelah panen menunjukkan nilai $\mathrm{pH}$ tanah untuk perlakuan kontrol 5,79, urea 5,79, SRU Bentonit 5,51, 
Tabel 4. Data hasil analisis tanah awal di Bukit Kemiling Permai, Kelurahan Kepayang, Kecamatan Kemiling, Kota Bandar Lampung.

\begin{tabular}{lcc}
\hline \multicolumn{1}{c}{ Parameter tanah } & Nilai & Kriteria \\
\hline $\mathrm{pH}$ & 6,07 & Agak asam \\
N-total (\%) & 0,13 & Rendah \\
C-organik (\%) & 1,67 & Rendah \\
P-tersedia (ppm) & 22,44 & Sangat tinggi \\
Kalium (K2O) (me/100g) & 0,906 & Tinggi \\
\hline
\end{tabular}

Tabel 5. Data hasil analisis pH tanah setelah panen di Bukit Kemiling Permai, Kelurahan Kepayang, Kecamatan Kemiling, Kota Bandar Lampung.

\begin{tabular}{|c|c|c|}
\hline Kode sampel & $\mathrm{pH}$ & Kriteria \\
\hline Kontrol & 5,79 & Agak asam \\
\hline Urea & 5,47 & Asam \\
\hline Bentonit & 5,51 & Asam \\
\hline $\mathrm{BBA}$ & 5,54 & Asam \\
\hline Messopori & 5,47 & Asam \\
\hline
\end{tabular}

SRU BBA 5,54, dan SRU Messopori 5,47 (Tabel 5). Pupuk yang mengandung nitrogen dalam bentuk amonia atau dalam bentuk lainnya dapat berubah menjadi nitrat yang berakibat pada penurunan $\mathrm{pH}$ tanah. Nitrifikasi berakibat dalam produksi ion-ion hidrogen dan berpotensi meningkatkan kemasaman tanah (Foth, 1995). Tanah yang baik untuk pertumbuhan kubis bunga adalah tanah yang subur, cukup air tapi tidak menggenang, berupa tanah lempung berpasir dengan pH 5,5-6,6 dan mengandung cukup bahan organik (Pracaya1999).

\section{KESIMPULAN}

Kesimpulan dari penelitian adalah pemberian pupuk sumber N jenis SRU tidak menunjukkan adanya perbedaan pada semua variabel pengamatan dibandingkan dengan pupuk urea konvensional. Sedangkan pada pemberian pupuk SRU (Slow Release Urea) jenis Bentonit cenderung menghasilkan bobot curd yang lebih tinggi dibandingkan dengan pupuk SRU (Slow Release Urea) jenis BBA (Bagasse Bottom Ash) dan Messopori dengan selisih 15,75 g per tanaman atau setara dengan $984 \mathrm{~kg} / \mathrm{ha}$.

\section{DAFTAR PUSTAKA}

Direktorat Budidaya Tanaman Sayuran dan Biofarmaka, Direktorat Jenderal Hortikultura. 2008. Standar Operasional Prosedur (SOP) Budidaya Sayuran Organik. Jakarta: Direktorat Budidaya Tanaman Sayuran dan Biofarmaka.

Ekaputri, Januari Jaya., Triwulan., dan Damayanti, Oktaviana. 2007. Sifat mekanik beton geopolimer berbahan dasar fly ash jawa power paiton sebagai material alternatif. pondasi. Volume 13 No2, ISSN 0985 814X.124 134.

Foth, HD 1995, Fundamentals of soil science, Terjemahan Purbayanti, ED, Lukiwati \& 
Trimulatsih, Gadjah Mada University Press, Yogyakarta.

Kalshoven, L.G.E. 1981. Pest of Crops in Indonesia. Revised and Translated by Van der Laan, P.A. PT. Ichtiar Baru-Van Hoeve. Jakarta.

Landschoot, P., 2015. Enhanced efficiency nitrogen fertilizers for turfgrasses. https://extension.psu. edu/enhanced-efficiency-nitrogen-fertilizersforturfgrasses/. (Accessed 1 October 2019).

Marliah A, Nurhayati, Riana R. 2013. Pengaruh varietas dan konsentrasi pupuk majemuk terhadap pertumbuhan dan hasil tanaman kubis bunga (Brassica oleracea L.). J Floratek 8: 118-126.

Pracaya. 1999. Kol alias Kubis. Panebar Swadaya. Jakarta.
Sunarti. 2015. Pengamatan Hama dan Penyakit Penting. Jurnal Agroqua. Vol. 13 No. 2:79.

Suryani, A. 2018. Uji aplikasi berbagai jenis pupuk slow release urea (SRU) dan pemberian NPK terhadap pertumbuhan tanaman kubis bunga (Brassica oleraceae var brotrytis L.). (Skripsi). Universitas Lampung. Bandar Lampung.

Sutedjo, M.M. 2010. Pupuk dan Cara Pemupukan. Rienekacipta. Jakarta. $8150 \mathrm{hlm}$.

Suwardi. 1991. The mineralogical and chemical properties of natural zeolite and their aplication effect for soil amandement. A thesis for the degree of masterlaboratory ofsoil science departemen of agriculture chemistry. TokyoUniversity of agriculture. 